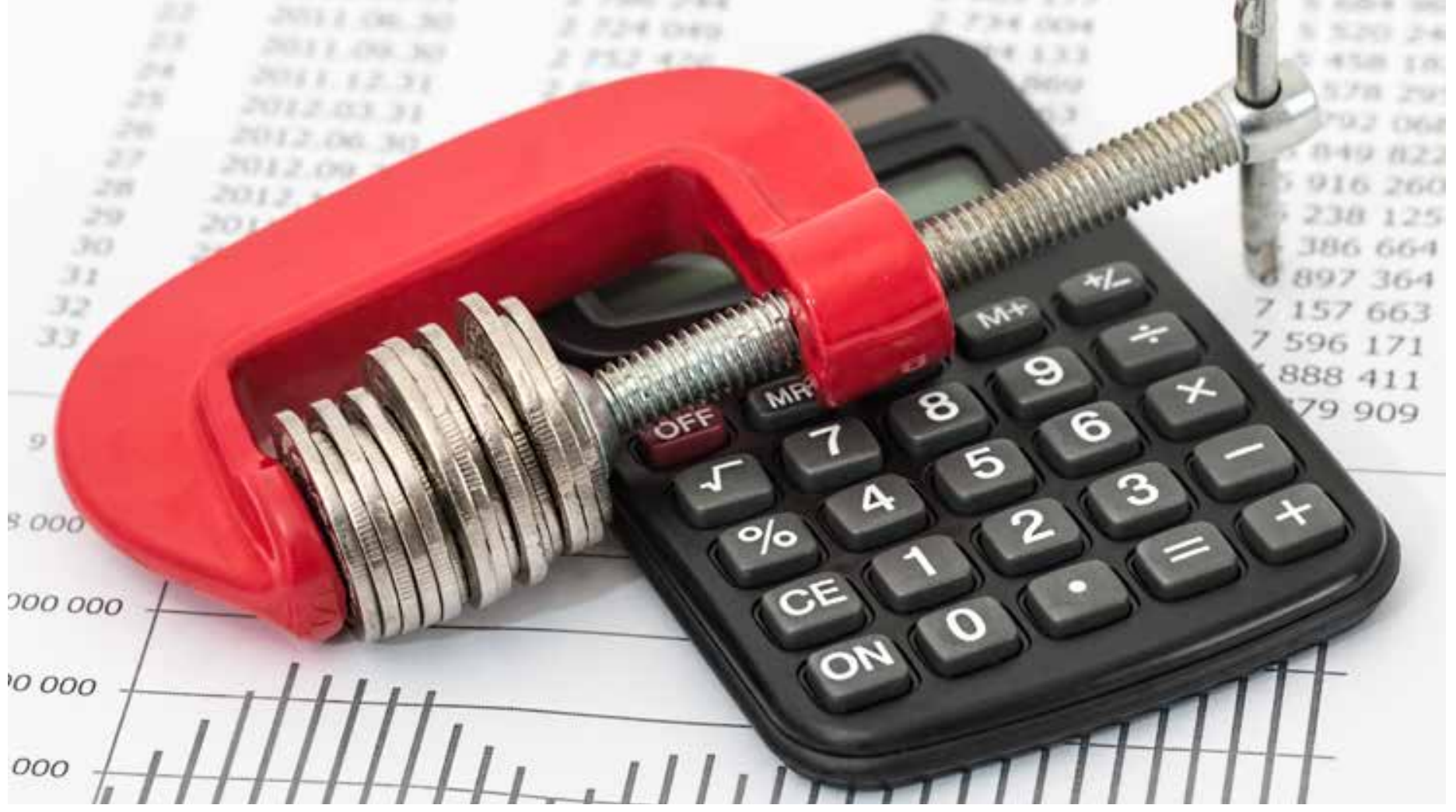

\title{
¿Una modernización tributaria o contra
}
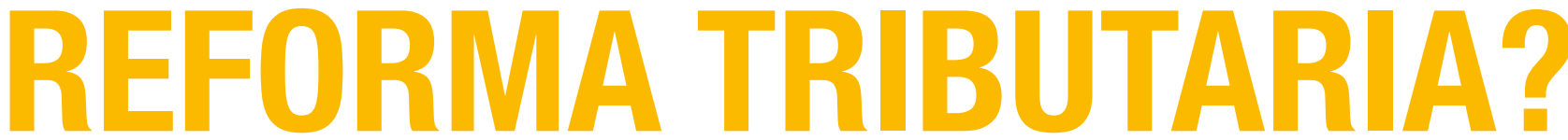

Humberto Borges, Doctor ( c) en Contabilidad y Finanzas Universidad de Zaragoza, España. MPGT USACH. Académico FEN UAH

Germán R. Pinto Perry, Doctor en Ciencias de la Administración, Director del Magister en Planificación y Gestión Tributaria - USACH, Académico FAE USACH.

\section{Las principales discusiones de la nueva reforma tributaria se han enfrascado en si el rótulo} de Modernización Tributaria es el correcto o si es mejor denominarla Contra Reforma Tributaria. Lo cierto es que hay que alejarse del eslogan y discutir los temas de fondo que llevaron a tener en la palestra nuevamente las leyes tributarias.

\section{DIVERSOS REGÍMENES, FALTA DE SIMPLIFICACIÓN Y EQUIDAD HORIZONTAL}

a actual convivencia de dos regímenes de tributación para las empresas y sus dueños genera una falta de equidad horizontal que pretende corregir el proyecto de reforma tributaria que fue enviado desde el Ejecutivo al Congreso.

La carga tributaria final, comprendida como la suma del Impuesto a la Renta de Primera Categoría (IRPC) más el Impuesto Global Complementario (IGC), resulta más alta en los contribuyentes acogidos a la letra $B$ del art. 14 de la Ley sobre Impuestos a la Renta (14B), que aquella que aplican los contribuyentes acogidos a la letra A del mencionado artículo (14A).

Esa diferencia está dada en la tasa del tribu- to de categoría que afecta a los contribuyentes $14 \mathrm{~B}$, que es un $27 \% \mathrm{y}$, además, se adiciona un impuesto de tasa plana que se produce cuando no se otorgan el $35 \%$ del crédito del IRPC en contra el IGC al inversor. Esto se diferencia de la tasa del $25 \%$ para el IRPC y la posibilidad de aplicar el $100 \%$ del crédito del IRPC contra el IGC que aplica a los contribuyentes 14A.

Esta desigualdad es un hecho y está claramente señalado por el legislador en las normas legales.

La falta de equidad horizontal se evidencia en dos contribuyentes con igual patrimonio, que pueden optar entre los regímenes del 14A 0 14B cuando pueden elegir, y se manifiesta, además, cuando algunos contribuyentes que tienen como dueño a una sociedad, hecho que lo inva- lida a optar al 14A, según expresamente señalan las normas legales, están impedidos de elegir y obligados a la adopción del 14B.

No resulta entendible por qué existen estos dos regímenes sin una diferencia que la justifique como sería el tamaño del patrimonio, como sí se aplica en el proyecto de reforma en trámite legal.

En efecto, el actual proyecto elimina el régimen $14 \mathrm{~A}$ y solo deja al sistema actual del 14B, pero dando el $100 \%$ del crédito del IRPC contra el IGC a los socios. A su vez, el proyecto en discusión concede un régimen de tributación con algunas simplificaciones para aquellos contribuyentes que pueden ser clasificados como pymes, para los cuales se aplica una renta atribuida (los dueños tributan en sus IGC automá- 


\begin{tabular}{|c|c|c|c|c|c|c|c|}
\hline Regimen & $\begin{array}{c}\text { Renta } \\
\text { Empresa }\end{array}$ & IRPC & $\%$ & Crédito a Socios & $\begin{array}{c}\% \\
\text { Sin derecho a } \\
\text { devolución }\end{array}$ & $\begin{array}{c}\% \\
--\end{array}$ \\
\hline $14 \mathrm{~A}$ & 100.000 & 25.000 & $25 \%$ & 25.000 & $17,55 \%$ & 9.450 \\
\hline $14 \mathrm{~B}$ & 100.000 & 27.000 & $27 \%$ & 17.550 & $9,45 \%$ \\
\hline
\end{tabular}

Ejemplo de créditos asociados a distintos regímenes 14A y 14B. Además, se visualiza el impuesto o plano del 9,45\%. La ley indica que sólo pueden recibir un crédito por IRPC equivalente al $65 \%$ por retiros y dividendos afectos a los IGC percibidos por empresas acogidas al régimen 14B, en el ejemplo son los 17.550 .

ticamente por las rentas de sus empresas) con una tasa del $25 \%$.

En este caso se aplica una distinta carga tributaria total a contribuyentes con diferencias patrimoniales, hecho que se permite al reconocer la equidad vertical.

Además, esta equidad puede ser observada como un desincentivo a la inversión. Los inversionistas de empresas acogidos al 14B, sólo pueden recibir un crédito por IRPC equivalente al $65 \%$ por retiros y dividendos afectos a los IGC percibidos por empresas acogidas al régimen $14 \mathrm{~B}$. En pocas palabras, un impuesto pagado de una empresa acogida a este régimen con utilidad tributable de $\$ 100$ paga $\$ 27 \mathrm{de} \mathrm{im-}$ puesto $(27 \%)$, para sus dueños o accionistas sólo tendrán derecho a $\$ 17,55$ de crédito (sólo el $65 \%$ de $\$ 27$ ) en contra de sus IGC, y los $\$ 9,45$ son un impuesto de tasa plana aplicada a la inversión. (Ver recuadro)

Este desincentivo se acrecienta al observar que esto ocurre sólo a las empresas nacionales cuando se invierte en el extranjero el total de lo pagado por impuestos en otros países es convertido en crédito, desfavoreciendo a la inversión nacional. Por otro lado, en el antiguo régimen, personas que ahorraban invirtiendo en acciones y que además eran no afectas a IGC por tener rentas bajas, como por ejemplo los jubilados de clase media, podían llegar a tener una devolución por impuestos, en la actual reforma son castigados por invertir en empresas. Para el gobierno actual y para el ministro Felipe

1. Ministro Larraín en Seminario CLAPES de la PUC “'Modernización o reforma tributaria?”, 13-09-2018

2. "Los nudos de la reforma Tributaria", El Mercurio, 21 de Octubre 2018

3. Idem.

4. H. Borges, "Herramienta estratégica para lograr Bienestar Social y Equidad”. Observatorio Económico $\mathrm{N}^{\circ} 126$ / mayo 2018.

\section{"El proyecto concede un} régimen de tributación con algunas simplificaciones para aquellos contribuyentes que pueden ser clasificados como pymes, para los cuales se aplica una renta atribuida (dueños tributan en sus IGC automáticamente por las rentas de sus empresas) con una tasa del $25 \%$ "

Larraín, esta tasa es como un impuesto plano, ${ }^{1}$ que se traduce en desincentivo a la inversión nacional.

En contra de la teoría de falta de equidad horizontal, el ex ministro Valdés indica que en el sistema integrado basado en retiro a una sociedad de inversiones le permite postergar impuestos, además, se puede redistribuir rentas para no pagar tributo².

\section{PRO PYMES}

Además, el proyecto enfatiza en aumentar el número de empresas que puedan acceder al 14 ter, aumentando el tramo de aceptación de Pymes a la facturación de 50.000 UF, en forma rápida y automática para todas las estructuras jurídicas, no discriminando a las SA. Si tiene una facturación de 10.000 UF, se le propondrá una renta con el pago de impuesto sobre el promedio de la industria sin revisión posterior, y si su facturación es de 50.000 UF la propuesta de declaración de impuesto será creada con la información electrónica que tiene el SII.

En primera instancia, se visualiza una no dis- criminación a PYMES constituidas como SA, que terminaron acogiéndose al $14 \mathrm{~B}$, con los trastornos antes explicados. Además, se puede observar una falencia en la propuesta de las empresas PYMES con facturación de 10.000 UF, pues la no revisión posterior puede dejar abierta la puerta a empresas de papel o a lavado de capitales. El ex ministro Valdés, en este punto, indicó que las rentas presuntas desincentivan la necesaria formalización ${ }^{3}$.

El proyecto, también incluye la institucionalización del "Defensor del contribuyente" que será un organismo público que mediará en las disputas entre el SII y los contribuyentes. Esta medida es curiosa, ya que el organismo fiscalizador siempre se ha lucido por su labor y ha sido premiado por sus funciones.

\section{COMPARACIÓN DE LOS INCENTIVOS SOCIALES}

Al comparar la reforma tributaria del Gobierno Bachelet II y propuesta del Gobierno Piñera II, el foco social fue solventar la educación superior en la primera, y en la actual se enfoca en solventar la ayuda a la región de la Araucanía, al mejorar el incentivo de depreciación acelerada a las empresas de la región y, además, favorecer las Zonas Extremas extendiendo la franquicia hasta el año 2.035 .

Otro punto, es modernizar y perfeccionar los impuestos verdes sobre actividades contaminantes, tema que no se ha profundizado. Además, nada se dice, como solventar el trabajo social empresarial, que se quiere producir entre gobierno y empresarios para solucionar los temas sociales.

Por último, una crítica que compartimos es dejar sin cambio el error profundo de disminuir la tasa de $40 \%$ a $35 \%$ al tramo con más ingreso en lo respectivo a IGC, la propuesta de reforma puede ser más favorable a las PYMES, pero sin duda, la recaudación quedó muy mermada al disminuir está tasa, además, de no ser equitativa entre los tramos de impuesto 4 . $\mathbf{E}$ 